\title{
Article \\ Effect of Coriolis Force on Vibration of Annulus Pipe
}

\author{
Gian Maria Santi *D, Daniela Francia (D) and Francesco Cesari
}

Department of Industrial Engineering-DIN, University of Bologna, Viale del Risorgimento 2, 40100 Bologna, Italy; d.francia@unibo.it (D.F.); francesco.cesari@unibo.it (F.C.)

* Correspondence: gianmaria.santi2@unibo.it

\begin{abstract}
Annulus pipe conveying fluids have many practical applications, such as hydraulic control lines and aircraft fuel lines. In some applications, these tubes are exposed to high speeds. Normally, this leads to a vibration effect which may be of a catastrophic nature. The phenomenon is not only driven by the centrifugal forces, but an important role is played also by the Coriolis forces. Many theoretical approaches exist for a simple configuration or a complex three-dimensional configuration. Finite element models are tested. This paper provides a numerical technique for solving the dynamics of annulus pipe conveying fluid by means of the mono-dimensional Finite Element Method (FEM). In particular, this paper presents a numerical solution to the equations governing a fluid conveying pipeline segment, where a Coriolis force effect is taken into consideration both for fix and hinge constraint.
\end{abstract}

Keywords: FEM; Coriolis; pipe conveying fluid; simulation

Citation: Santi, G.M.; Francia, D.; Cesari, F. Effect of Coriolis Force on Vibration of Annulus Pipe. Appl. Sci. 2021, 11, 1058. https://doi.org/ 10.3390/app11031058

Academic Editor: Marek Krawczuk Received: 23 December 2020 Accepted: 21 January 2021 Published: 25 January 2021

Publisher's Note: MDPI stays neutral with regard to jurisdictional clai$\mathrm{ms}$ in published maps and institutional affiliations.

Copyright: (C) 2021 by the authors. Licensee MDPI, Basel, Switzerland. This article is an open access article distributed under the terms and conditions of the Creative Commons Attribution (CC BY) license (https:// creativecommons.org/licenses/by/ $4.0 /)$.

\section{Introduction and Background}

Fluid conveying pipes [1] are attractive form an engineering point of view because the instability effects can be a dangerous structural weakness. These systems interact with axial flows in flexible conduits with prevalent applications in the oil and gas production industries. Examples of these practical applications can be found in [2]. However, the examples found in the literature are not only limited to the field of engineering but cut across other areas of human endeavor, such as the study of pulmonary and urinary tract systems or even hemodynamics within human physiology. A lot of research interest is now focused on models for studying the stability of certain classes of dynamical systems, finding novel numerical and analytical methods for solving such problems. Thus, for linear dynamics for axial flows along slender structures, the pipe conveying fluid is regarded as the main paradigm. Direct applications in technical fields can be found in the behavior of aspirating pipes for ocean mining and Liquefied Natural Gas (LNG) in situ production, as well as for the offshore mining of methane liquid-crystal deposits and carbon sequestration. Flow-induced vibrations and instabilities are seeking to be resolved by simple, fast, and robust models.

Many researchers developed different methodologies to study the problem [3-5]. In particular, the Coriolis force became important in the analysis of stability, due to its role in the energy equation. Studies can be found in [6-8]. Helped by the experiments described in $[9,10]$ it was possible to assume that the contribution of both the Coriolis force and the centrifugal force lead to flutter effects that can be dangerous for the strength of the structure. In [11], Eriksson et al. investigated the impact of the Coriolis force on the long distance wake behind wind farms by using Large Eddy Simulations (LES) combined with a Forced Boundary Layer (FBL) technique. The results indicate that FBL can be used for studies of long distance wakes without including a Coriolis correction, but efforts need to be taken to use a wind shear with a correct mean wind veer. The subject of piping vibration has attracted a lot of attention from various researchers in recent times, due to vast applications. In [12] Shaik et al. described a vibration analysis and mathematical 
model using Euler-Bernoulli and Hamilton's energy expressions for fluid conveying a welded galvanized iron pipe with a clamped-clamped boundary condition. Many other attempts concerning the fluid conveying pipe vibrations were made and different analytical methods were applied and compared to numerical solutions by software. Avinash B. Kokare et al. [13], studied the vibrational characteristics of pipe conveying fluid and FE simulation to evaluate velocity and pressure distribution in a single phase fluid flow. Gongfa Li et al. [14] obtained the element standard equation for natural frequencies by the Lagrangian interpolation function, the first order Hermite interpolation function, and the Ritz method. Wentao Xiao et al. [15] used the Lagrangian interpolation function, the first order Hermit interpolation function, and the Ritz method to obtain the element standard equation for the nonlinear vibration response and then integrated a global matrix equation, obtaining the response of a conveying fluid pipe with the New Mark method and Matlab. Muhsin J. Jweeg et al. [16] compared results obtained by experimental verification with the aid of Smart Materials with the results performed by using analytical solution for equation of motion and also, with the results performed by using ANSYS Software. The field of nanostructures is currently turning to vibration issues and their formulation as well. Carbon nanotubes (CNTs) have been extensively used in numerous areas, due to their excellent mechanical properties. As an important mechanical property, the vibration characteristics of a CNT have become another hot topic for research in recent years. In [17], the spectral element method (SEM) is applied to analyze the dynamic characteristics of fluid conveying single-walled carbon nanotubes (SWCNTs).

\section{Objectives}

This paper proposes a solution to the pipe conveying fluid with Coriolis forces using a simple one-dimensional Finite Element Method with a Hermitian shape function. In particular, the modal frequencies and the critical frequencies are analyzed by changing the velocity field of the fluid. An imaginary solution is taken into account for the problem, as shown in the following. Mono-dimensional elements make possible the solution of simple numerical problems for a complex phenomena, avoiding large Fluid Structure Simulations (FSI) with difficult boundary conditions and numerical issues. In [18], an extensive literature review on the state-of-the-art numerical models in 1D, the FluidStructure Interaction is proposed. In the presented paper, two systems are studied: a double fixed pipe and a hinged pipe to its boundary. The first system is mostly theoretical, while the hinged pipe is more representative of the true environment that can occur in a real application. Engineering solutions are presented for the latter problem, but many other fields can be researched, such as pulmonary and urinary tract systems in the human endeavor area, highlighting the importance of simple and fast numerical methods for the analysis.

\section{Methodology}

In the modeling of the mechanics of fluid conveying pipes, the Coriolis force was assigned to have the role of energy absorption that counters the centrifugal effect that normally arises in free motions, affecting the stability in conservative and nonconservative systems, as reported in [1,6-8,19-26]. For example, in [27], sewer condition prediction models are developed to provide a framework to forecast future conditions of pipes and to schedule inspection frequencies. Furthermore, in [28], the finite-element method was effectively used to model the soil-pipe interaction for five full-scale laboratory tests conducted on a steel pipe. Such models can be used for the analysis of flexible pipe embedment design for layered embedment conditions.

\subsection{Analytical Approach}

From the studies reported in [29-31], the analytical expression for the motion equation can be written. Let us start by assuming that the curvature of a pipe in which a fluid flows with a velocity $v$ depends on the transversal displacement $w$ caused by its weight, 
the external forces and the internal forces. Let us assume that $m$ is the total mass of fluid and pipe and $\rho$ is the mass of fluid per length span. If the pipe is immersed in the fluid, it is possible to sum the mass of the external fluid to the mass of the pipe, and it can be calculated by multiplying the density of the fluid itself times the area of the considered section. The forces acting on the element $d x$ of the pipe are:

- $\quad m \ddot{w}=$ inertia force due to the vertical acceleration of the pipe;

- $E J w^{\prime \prime \prime}=$ elastic forces due to Euler-Bernoulli's theory.

$E$ is the Young module of the material, $J$ is the inertia moment of the geometry, and the derivatives over time and space of the displacement $w$ are defined as follows:

$$
\dot{w}=\frac{d w}{d t}, \quad w^{\prime}=\frac{d w}{d x}, \quad w^{\prime \prime}=\frac{d^{2} w}{d x^{2}}, \quad \omega=\dot{w}^{\prime}=\frac{d^{2} w}{d t d x}
$$

When a fluid is flowing in a pipe, and it is subjected to the Coriolis acceleration [32] through the mechanical introduction of the apparent rotation into the pipe, the amount of deflecting force generated by the Coriolis inertial effect will be a function of the mass flow rate of the fluid. If a pipe is rotated around a point while a liquid is flowing through it, that fluid will generate an inertial force acting on the pipe that will be at right angles to the direction of the flow.

Figure 1 shows the entire methodology, and Figure 2 shows a particle $d m$ traveling at a velocity $v$ inside a tube. The tube is rotating around a fixed point $P$, and the particle is at a distance of one radius $r$ from the fixed point. The particle moves with an angular velocity $\omega$ under two components of acceleration, a centripetal acceleration directed toward $P$, and a Coriolis acceleration acting at right angles

- $\quad a_{r}($ centripetal $)=\omega^{2} r$

- $a_{t}$ (Coriolis) $=2 \omega v$

Moreover, when the pipe deflects, a centripetal force acts on an element $d x$ of mass $d m$ that tends to move the pipe back to the equilibrium position. If $R$ is the curvature radius, the result is:

$$
d F=d m \frac{v^{2}}{R} \approx d m v^{2} w^{\prime \prime} d x
$$

Substituting $d m=\rho d x$

$$
d F=-\rho v^{2} w^{\prime \prime} d x
$$

The sign '-' appears because the force $d F$ with positive curvature points to the opposite direction with respect to the displacement $w$. Because of that, the forces imposed by the fluid to the pipe per unit length neglecting $a_{r}$ are:

$$
\begin{aligned}
& F_{t}=2 \rho v \dot{w}^{\prime} \\
& F=\rho v^{2} w^{\prime \prime}
\end{aligned}
$$

and the equation of motion becomes:

$$
E J \frac{\partial^{4} w}{\partial x^{4}}+m \frac{\partial^{2} w}{\partial t^{2}}+\rho v^{2} \frac{\partial^{2} w}{\partial x^{2}}+2 \rho v \frac{\partial^{2} w}{\partial t \partial x}=0
$$

Before reducing Equation (1) to its dimensional form, it is possible to write down the integration form that represents the potential energy equation without considering Neumann boundary conditions

$$
\Pi=\frac{1}{2} \int_{0}^{L}\left(E J\left(\frac{\partial^{2} w}{\partial x^{2}}\right)^{2}+\frac{\rho v^{2}}{2}\left(\frac{\partial w}{\partial x}\right)^{2}+2 \rho v \frac{\partial^{2} w}{\partial t \partial x}+m \frac{\partial^{2} w}{\partial t^{2}} w\right) d x+W
$$


where $W$ is the work of external loads. Interpolating the displacement field using the Hermitian shape function, separating the variables

$$
\left\{\begin{array}{l}
w(x, t)=\Delta^{T}(t) N(x) \\
\Delta(t)=\left(w_{1}, \phi_{1}, w_{2}, \phi_{2}\right)
\end{array}\right.
$$

where $\Delta(t)$ is the vector of displacements and rotation referred to each node of the finite element. In particular, the considered element is a mono-dimensional element with two nodes where the subscripts 1 and 2 indicate the quantities related to the first or the second node. Applying the principle of virtual displacement [33]:

$$
\delta \Pi=0
$$

substituting Equation (3) in Equation (2) and imposing Equation (4) lead to

$$
\delta \Delta^{T} \int_{0}^{L}\left(m \ddot{\Delta}^{T} N N^{T}+E J\left(N^{\prime \prime}\right)^{T}+2 \rho v\left(\dot{\Delta}^{T} N^{\prime}\right) N^{T}+\rho v^{2} \Delta^{T} N^{\prime} N^{\prime T}\right) d x=\delta \Delta^{T} R
$$

where $\delta$ indicates the variation of the quantities described in the vector $\Delta$. Reordering the members in order to form matrices result in:

$$
M \ddot{\Delta}+C \dot{\Delta}+E J\left(K-K_{n l}\right) \Delta=R
$$

$M, K, C$, and $K_{n l}$ are matrices defined in the following section and $R$ is the residual matrix.

\subsection{FEM Approach}

In Equation (6) $M, K, C$, and $K_{n l}$ are defined as:

$$
M=\int_{0}^{L} m N N^{T} d x, \quad K=\int_{0}^{L} E J\left(N^{\prime \prime}\right)^{T} d x, \quad C=\int_{0}^{L} 2 \rho v N^{\prime} N^{T} d x, \quad K_{n l}=\int_{0}^{L} \rho v^{2} N^{\prime} N^{\prime T} d x
$$

In order to use the FEM theory, it is important to integrate all the matrices in the local reference system, where the shape functions are defined as follow:

$$
\left\{\begin{array}{l}
N_{1}=\frac{1}{4}\left(2-3 \xi+\xi^{3}\right) \\
N_{2}=\frac{L}{8}\left(1-\xi-\xi^{2}+\xi^{3}\right) \\
N_{3}=\frac{1}{4}\left(2+3 \xi-\xi^{3}\right) \\
N_{4}=\frac{L}{8}\left(-1-\xi+\xi^{2}+\xi^{3}\right)
\end{array}\right.
$$

\subsubsection{Fixed Pipe}

Let us now consider a pipe fixed to its end nodes and defined by two finite elements. These two elements have the same length $L$ and the total amount of degrees of freedom is two, as shown in Figure 3. 


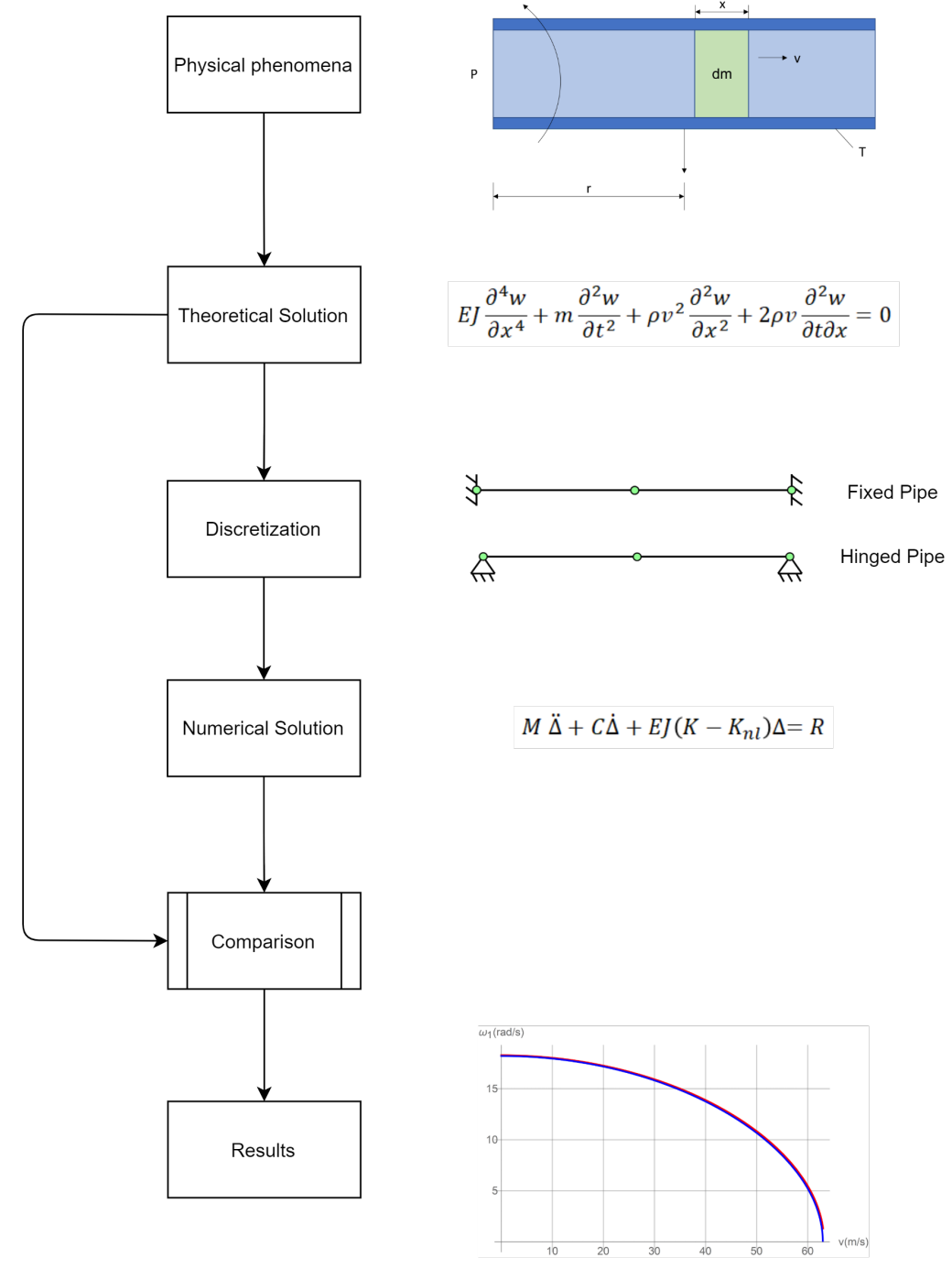

Figure 1. Methodology flow chart.

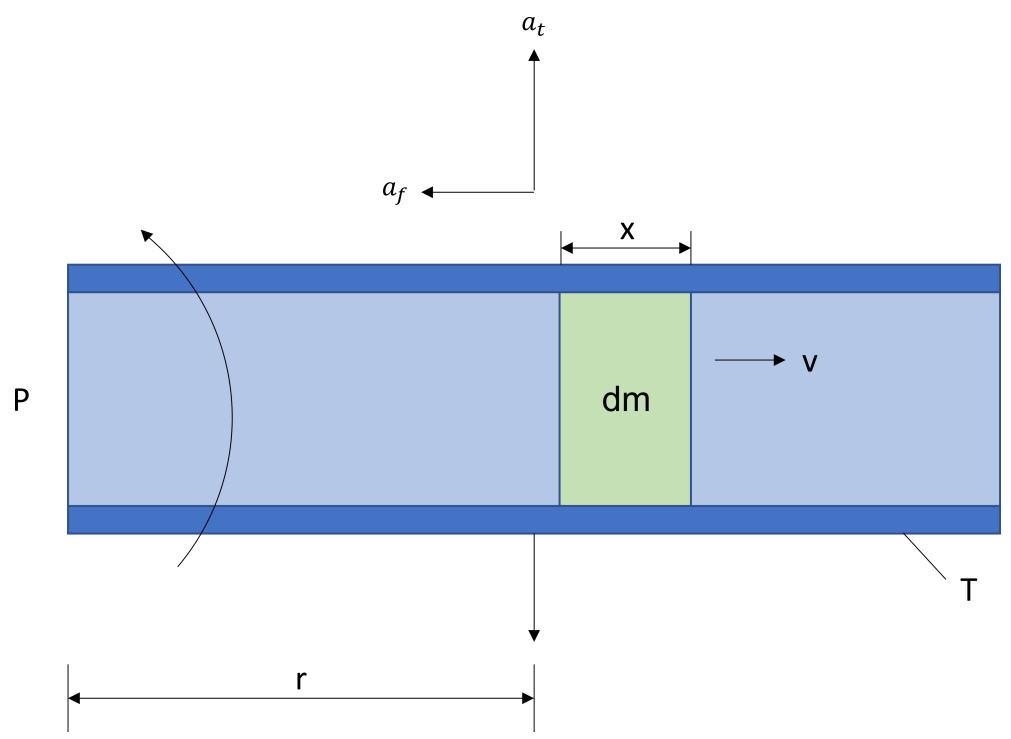

Figure 2. Fluid moving through a pipe. 


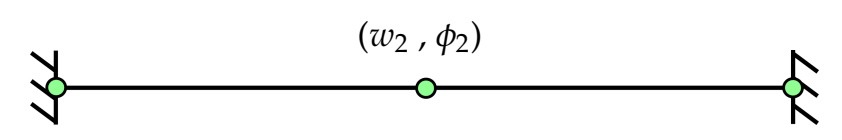

Figure 3. Element representation of the pipe fixed to its boundary nodes.

The motion equation becomes

$$
m\left(\begin{array}{cc}
\frac{26 L}{35} & 0 \\
0 & \frac{2 L^{3}}{105}
\end{array}\right)\left(\begin{array}{c}
\ddot{w}_{2} \\
\ddot{\phi}_{2}
\end{array}\right)+2 \rho v\left(\begin{array}{cc}
0 & -\frac{L}{5} \\
\frac{L}{5} & 0
\end{array}\right)\left(\begin{array}{c}
\dot{w}_{2} \\
\dot{\phi_{2}}
\end{array}\right)+\left(E J\left(\begin{array}{cc}
\frac{24}{L} & 0 \\
0 & \frac{8}{L}
\end{array}\right)-\rho v^{2}\left(\begin{array}{cc}
\frac{12}{5 L} & 0 \\
0 & \frac{4 L}{15}
\end{array}\right)\right)\left(\begin{array}{c}
w_{2} \\
\phi_{2}
\end{array}\right)=\left(\begin{array}{c}
F_{2} \\
M_{2}
\end{array}\right)
$$

The system is now ready to be solved by determining the values of natural frequencies while the velocity changes. In particular, the load vector is set equal to zero while the displacement $w$ and the rotation $\phi$ are defined as an exponential function in the complex domain $(\mathbb{C})$ multiplied to a unknown constant ( $W$ for displacement and $\Phi$ for rotation):

$$
\left\{\begin{array} { l } 
{ w _ { 2 } = W e ^ { i \omega t } } \\
{ \dot { w } _ { 2 } = \partial _ { t } w _ { 2 } } \\
{ \ddot { w } _ { 2 } = \partial _ { t , t } w _ { 2 } }
\end{array} \quad \left\{\begin{array}{l}
\phi_{2}=\Phi e^{i \omega t} \\
\dot{\phi}_{2}=\partial_{t} \phi_{2} \\
\ddot{\phi}_{2}=\partial_{t, t} \phi_{2}
\end{array}\right.\right.
$$

Substituting Equation (9) in Equation (8) and dividing everything by $e^{i \omega t}$ results in:

$$
\left(\begin{array}{c}
-\frac{2\left(-420 E J W+42 L^{2} v^{2} W \rho+L^{4} \omega(7 i v \rho \Phi+13 m W \omega)\right)}{35 L^{3}} \\
\frac{8 E J \Phi}{L}-\frac{2}{105} L\left(14 v^{2} \rho \Phi-21 i v W \rho \omega+L^{2} m \Phi \omega^{2}\right)
\end{array}\right)=0
$$

that can be transformed in the following homogeneous system collecting the coefficients of $w$ and $\phi$

$$
\left(\begin{array}{ll}
A_{11} & A_{12} \\
A_{21} & A_{22}
\end{array}\right)\left(\begin{array}{l}
w \\
\phi
\end{array}\right)=0
$$

excluding the trivial solution of the Equation (10), it is possible to find the eigenvalues substituting $\omega^{2}$ with $\lambda$ and solving

$$
\operatorname{Det}\left[\mathbf{A}^{f i x}\right]=0
$$

where

$$
\mathbf{A}^{f i x}=\left(\begin{array}{ll}
A_{11} & A_{12} \\
A_{21} & A_{22}
\end{array}\right)
$$

leading to

$$
\left\{\begin{aligned}
\lambda_{1} & =-\frac{1}{26 L^{8} m^{2}} 7\left(-840 E J L^{4} m+32 L^{6} m v^{2} \rho-21 L^{6} v^{2} \rho^{2}+\left(L ^ { 8 } \left(518400 E J^{2} m^{2}\right.\right.\right. \\
& \left.\left.\left.-720 E J L^{2} m v^{2}(40 m-49 \rho) \rho+L^{4} v^{4} \rho^{4}\left(400 m^{2}-1344 m \rho+441 \rho^{2}\right)\right)\right)^{1 / 2}\right) \\
\lambda_{2} & =\frac{1}{26 L^{8} m^{2}} 7\left(840 E J L^{4} m-32 L^{6} m v^{2} \rho+21 L^{6} v^{2} \rho^{2}+\left(L ^ { 8 } \left(518400 E J^{2} m^{2}\right.\right.\right. \\
& \left.\left.\left.-720 E J L^{2} m v^{2}(40 m-49 \rho) \rho+L^{4} v^{4} \rho^{4}\left(400 m^{2}-1344 m \rho+441 \rho^{2}\right)\right)\right)^{1 / 2}\right)
\end{aligned}\right.
$$

The corresponding eigenvector associated to these eigenvalues describes the vibration modes of the structure. For a better representation, it is worth to transform the characteristic polynomial in its dimensionless form, introducing

$$
\begin{gathered}
\theta=\frac{L^{2} v^{2} \rho}{E J} \\
\eta=\frac{\rho}{m}
\end{gathered}
$$


so the power of the frequency is

$$
\begin{aligned}
& \omega^{2}=\frac{E J}{L^{4} m}\left(226.2+\theta(-8.165+5.654 \eta) \pm 0.0385\left(2.54 e^{7}+\right.\right. \\
& \left.\left.10^{6} \theta(-1.410+1.729 \eta)+\theta^{2}\left(19600-65856 \eta+21609 \eta^{2}\right)^{1 / 2}\right)\right)
\end{aligned}
$$

and finally:

$$
\Psi=\sqrt{\frac{L^{4} m}{E J}} \omega=\sqrt{*}
$$

\subsubsection{Hinged Pipe}

Let us now consider a pipe hinged to its end nodes and defined with two finite elements. These two elements have the same length $L$ and the total amount of degrees of freedom is 4, as shown in Figure 4.

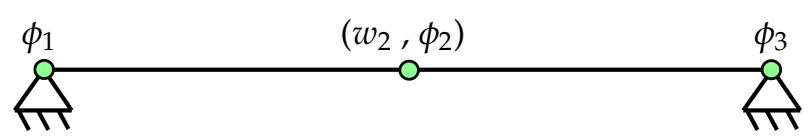

Figure 4. Element representation of the pipe hinged to its boundary nodes.

In this case, the elements of the Equation (6) are defined for four degrees of freedom derived from the imposed boundary condition and result in:

$$
\begin{gathered}
K=\frac{E L}{L^{3}}\left(\begin{array}{cccc}
4 L^{2} & -6 L & 2 L^{2} & 0 \\
-6 L & 12 & -6 L & 0 \\
2 L^{2} & -6 L & 4 L^{2} & 0 \\
0 & 0 & 0 & 0
\end{array}\right)+\frac{E L}{L^{3}}\left(\begin{array}{cccc}
0 & 0 & 0 & 0 \\
0 & 12 & 6 L & 6 L \\
0 & 6 L & 4 L^{2} & 2 L^{2} \\
0 & 6 L & 2 L^{2} & 4 L^{2}
\end{array}\right) \\
M=\frac{m L}{420}\left(\begin{array}{cccc}
4 L^{2} & 13 L & -3 L^{2} & 0 \\
13 L & 156 & -22 L & 0 \\
-3 L^{2} & -22 L & 4 L^{2} & 0 \\
0 & 0 & 0 & 0
\end{array}\right)+\frac{m L}{420}\left(\begin{array}{cccc}
0 & 0 & 0 & 0 \\
0 & 156 & 22 L & -13 L \\
0 & 22 L & 4 L^{2} & -3 L^{2} \\
0 & -13 L & -3 L^{2} & 4 L^{2}
\end{array}\right) \\
C=\frac{2 \rho v}{60}\left(\begin{array}{cccc}
0 & -6 L & L^{2} & 0 \\
6 L & 30 & -6 L & 0 \\
L^{2} & 6 L & 0 & 0 \\
0 & 0 & 0 & 0
\end{array}\right)+\frac{2 \rho v}{60}\left(\begin{array}{cccc}
0 & 0 & 0 & 0 \\
0 & -30 & -6 L & 6 L \\
0 & 6 L & 0 & L^{2} \\
0 & -6 L & -L^{2} & 0
\end{array}\right) \\
K_{n l}=\rho v^{2}\left(\begin{array}{ccccc}
\frac{2 L}{15} & -\frac{1}{10} & -\frac{L}{30} & 0 \\
-\frac{1}{10} & \frac{6}{5 L} & -\frac{1}{10} & 0 \\
-\frac{L}{30} & -\frac{1}{10} & \frac{2 L}{15} & 0 \\
0 & 0 & 0 & 0
\end{array}\right)+\rho v^{2}\left(\begin{array}{cccc}
0 & 0 & 0 & 0 \\
0 & \frac{6}{5 L} & \frac{1}{10} & \frac{1}{10} \\
0 & \frac{1}{10} & \frac{2 L}{15} & -\frac{L}{30} \\
0 & \frac{1}{10} & -\frac{L}{30} & \frac{2 L}{15}
\end{array}\right)
\end{gathered}
$$

Following the procedure of the previous case, the unknown quantities are expressed as follows:

$$
\left\{\begin{array} { l } 
{ w _ { 2 } = W e ^ { i \omega t } } \\
{ \dot { w } _ { 2 } = \partial _ { t } w _ { 2 } } \\
{ \ddot { w } _ { 2 } = \partial _ { t , t } w _ { 2 } }
\end{array} \quad \left\{\begin{array} { l } 
{ \phi _ { 1 } = \Phi e ^ { i \omega t } } \\
{ \dot { \phi _ { 1 } } = \partial _ { t } \phi _ { 1 } } \\
{ \ddot { \phi _ { 1 } } = \partial _ { t , t } \phi _ { 1 } }
\end{array} \quad \left\{\begin{array} { l } 
{ \phi _ { 2 } = \Phi e ^ { i \omega t } } \\
{ \dot { \phi _ { 2 } } = \partial _ { t } \phi _ { 2 } } \\
{ \ddot { \phi _ { 2 } } = \partial _ { t , t } \phi _ { 2 } }
\end{array} \quad \left\{\begin{array}{l}
\phi_{3}=\Phi e^{i \omega t} \\
\dot{\phi_{3}}=\partial_{t} \phi_{3} \\
\ddot{\phi_{3}}=\partial_{t, t} \phi_{3}
\end{array}\right.\right.\right.\right.
$$

Substituting Equation (15), Equation (14) in Equation (6), dividing by $e^{i \omega t}$ and collecting the coefficient of $\omega$ and $\phi$, it is possible to build the homogeneous system 


$$
\left(\begin{array}{llll}
A_{11} & A_{12} & A_{13} & A_{14} \\
A_{21} & A_{22} & A_{23} & A_{24} \\
A_{31} & A_{32} & A_{33} & A_{34} \\
A_{41} & A_{42} & A_{43} & A_{44}
\end{array}\right)\left(\begin{array}{l}
w \\
\phi_{1} \\
\phi_{2} \\
\phi_{3}
\end{array}\right)=0
$$

Again, excluding the trivial solution, the natural frequencies are found solving

$$
\operatorname{Det}\left[\mathbf{A}^{\text {hinge }}\right]=0
$$

where

$$
\mathbf{A}^{\text {hinge }}=\left(\begin{array}{llll}
A_{11} & A_{12} & A_{13} & A_{14} \\
A_{21} & A_{22} & A_{23} & A_{24} \\
A_{31} & A_{32} & A_{33} & A_{34} \\
A_{41} & A_{42} & A_{43} & A_{44}
\end{array}\right)
$$

\section{Results and Discussions}

The results are presented as a comparison between theoretical and numerical solutions for simple applications. In particular, a fixed pipe and a hinged pipe are taken into account as case studies. In both cases, the natural frequencies, due to the geometry only and the vibration modes relative to the inner fluid velocity, are calculated. A steel pipe filled with water is considered for both applications.

Table 1 shows the data for the following problems. $L$ is the total length, $A$ is the section area, $\rho$ is the fluid density, $D$ is the diameter, $d$ is the thickness, $E$ is the Young module of the steel, and $m_{1}, m_{2}$ are the two masses of the fluid and the pipe.

Table 1. Input data for a steel pipe filled with water.

\begin{tabular}{ccc}
\hline$L=4 \mathbf{~ m}$ & $D=\mathbf{0 . 1} \mathbf{~ m}$ & $d=\mathbf{0 . 0 9 5} \mathbf{~}$ \\
\hline$A=\frac{\pi d^{2}}{4} \mathrm{~m}^{2}$ & $E=2 \cdot 10^{11} \mathrm{~Pa}$ & $J=\frac{\pi\left(D^{2}-d^{2}\right)}{\left(D^{2}-d^{2}\right.}$ \\
$\rho=1000 \frac{\pi d^{2}}{4}$ & $m_{1}=\frac{\pi\left(D^{2}-d^{2}\right)}{4} 7800+1000 A$ & $m_{2}=\frac{\pi\left(D^{2}\right.}{4} 7800$ \\
\hline
\end{tabular}

\subsection{Fixed Pipe}

Considering the pipe only $(\eta=\theta=0$ because the mass of the fluid $\rho=0)$, Equation (13) lets us calculate the two natural frequencies:

$$
\left\{\begin{array}{l}
\Psi_{1}=5.684 \\
\Psi_{2}=20.494
\end{array}\right.
$$

against the theoretical values:

$$
\left\{\begin{array}{l}
\Psi_{1 t}=5.593 \\
\Psi_{2 t}=15.417
\end{array}\right.
$$

In particular, the critical loads are calculated solving

$$
\operatorname{Det}\left[E J\left(\begin{array}{cc}
\frac{24}{L^{3}} & 0 \\
0 & \frac{8}{L}
\end{array}\right)+\rho v^{2}\left(\begin{array}{cc}
-\frac{12}{5 L} & 0 \\
0 & -\frac{4 L}{15}
\end{array}\right)\right]=0
$$

thus

$$
\left\{\begin{array}{l}
\theta=10 \\
\theta=30
\end{array}\right.
$$

Figure 5 shows the decrease of the frequencies increasing the velocities of the flow underlying the critical values for the pipe instability (dotted lines). 


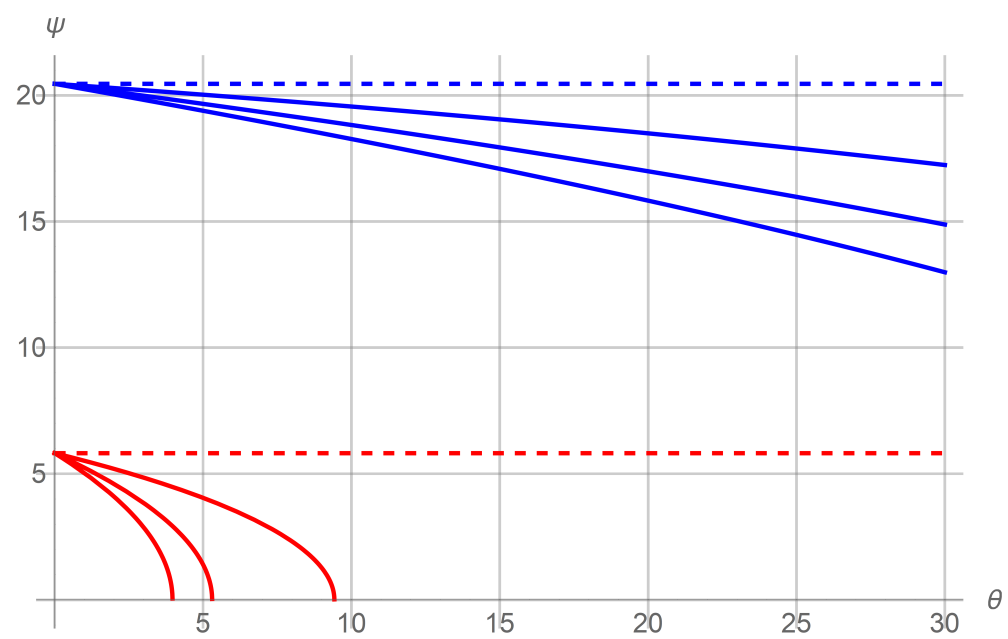

Figure 5. Frequencies with respect to the velocity.

Solving Equation (18) for the data reported in Table 1, lead to these four critical velocities of the pipe:

$$
\left\{\begin{array}{l}
v=-219.481 \\
v=-126.717 \\
v=126.717 \\
v=219.481
\end{array}\right.
$$

The results for the void tube with no velocity are described solving Equation (11) imposing $\rho=0, v=0$ and $m=m_{2}$. The frequencies are:

$$
\left\{\begin{array}{l}
\omega=-223.653 \\
\omega=-62.0302 \\
\omega=62.0302 \\
\omega=223.653
\end{array}\right.
$$

Following the same path but considering a tube filled with water with zero velocity $\left(\rho=1000 A, v=0\right.$ and $\left.m=m_{1}\right)$ results in

$$
\left\{\begin{array}{l}
\omega=-151.244 \\
\omega=-41.9475 \\
\omega=41.9475 \\
\omega=151.244
\end{array}\right.
$$

Finally, Figure 6 shows the curves of critical frequencies $\omega$ with respect to the fluid velocity $v$ for the first quadrant of the graph. 


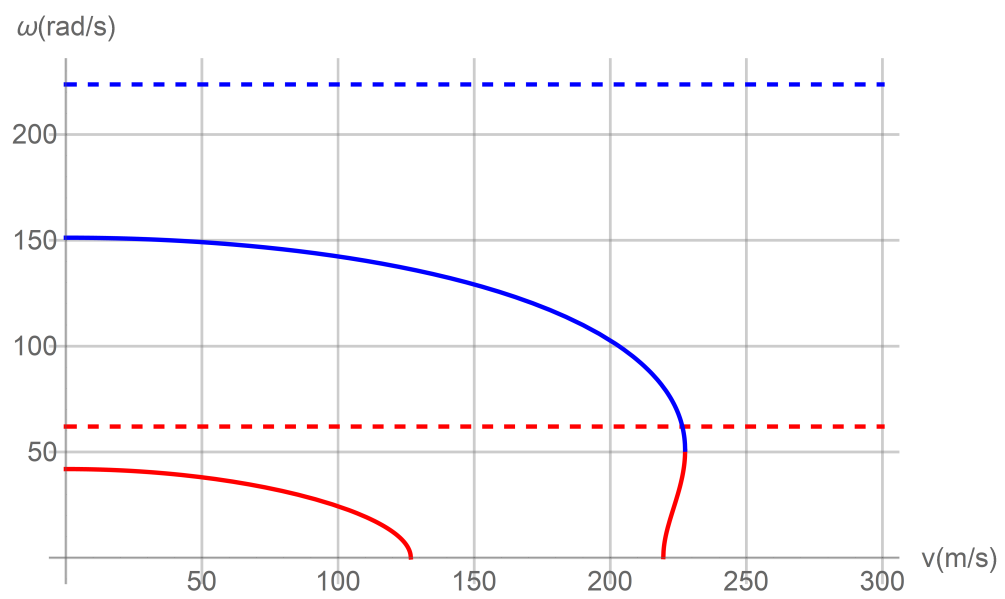

Figure 6. Frequencies respect to the velocity.

\subsection{Hinged Pipe}

Considering the pipe only and solving Equation (17), it is possible to evaluate the frequencies:

$$
\begin{array}{cccc}
\omega=-2.47714 \sqrt{\frac{E J}{L^{4} m}} & \omega=2.47714 \sqrt{\frac{E J}{L^{4} m}} & \omega=-27.5349 \sqrt{\frac{E J}{L^{4} m}} & \omega=27.5349 \sqrt{\frac{E J}{L^{4} m}} \\
\omega=-\frac{10.9545 \sqrt{E J}}{L^{2} \sqrt{m}} & \omega=\frac{10.9545 \sqrt{E J}}{L^{2} \sqrt{m}} & \omega=-\frac{50.1996 \sqrt{E J}}{L^{2} \sqrt{m}} & \omega=\frac{50.1996 \sqrt{E J}}{L^{2} \sqrt{m}}
\end{array}
$$

and the theoretical value is:

$$
\omega_{t}=\frac{\pi^{2}}{4 L^{2}} \sqrt{\frac{E J}{\rho}}
$$

Introducing $m=m_{1}$ for the fluid mass, it is possible to calculate the frequencies, due to the water velocity. Figure 7 shows the result for the first frequency.

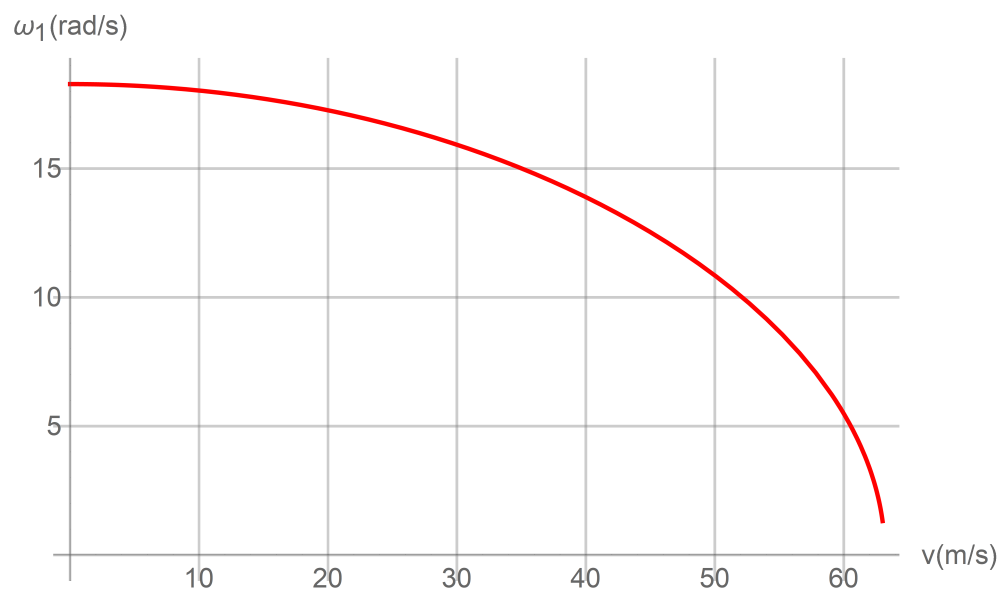

Figure 7. Frequencies with respect to the velocity.

Figure 8 shows all the four frequencies associated with the finite element solution of the hinged structure. 


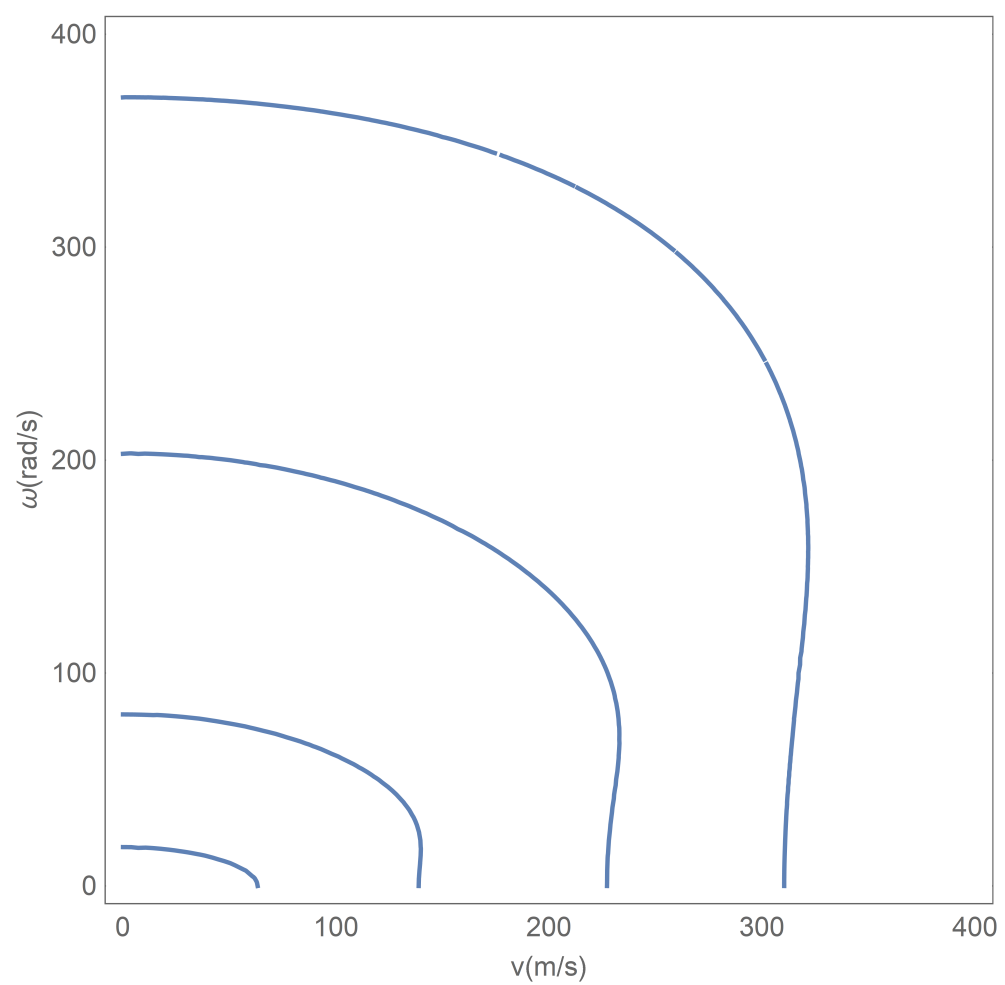

Figure 8. Frequencies with respect to the velocity.

In this specific application, a comparison with the theoretical solution is possible since and the analytical solution is known:

$$
w(x, t)=\sum_{n} A_{2_{n-1}} \operatorname{Sin}\left((2 n-1) \frac{\pi x}{L}\right) \operatorname{Sin}\left(\omega_{i} t\right)+\sum_{m} A_{2_{m}} \operatorname{Sin}\left(2 m \frac{\pi x}{L}\right) \operatorname{Cos}\left(\omega_{i}\right) t
$$

Equation (19) is substituted in Equation (1). The result can be rewritten by grouping the trigonometric terms and, in particular, it is possible to expand with a Fourier series the cosines terms:

$$
\begin{gathered}
\operatorname{Cos}\left(\frac{(-1+2 n) \pi x}{L}\right)=\sum_{m} \frac{2 n-1}{(2 n-1)^{2}-(2 m)^{2}} \\
\operatorname{Cos}\left(\frac{2 m \pi x}{L}\right)=\sum_{m} \frac{2 m}{(2 m)^{2}-(2 n-1)^{2}}
\end{gathered}
$$

Setting the similar trigonometric terms equal to zero and deleting all the modes except for the first two, the following condition can be written from the homogeneous system

$$
-\frac{32 \rho v \omega}{3 L\left(\frac{E J \pi^{4}}{L^{4}}-\frac{\pi^{2} v^{2} \rho}{L^{2}}-m \omega^{2}\right)}=-\frac{3 L}{8 \rho v \omega}\left(\frac{16 E J \pi^{4}}{L^{4}}-\frac{4 \pi^{2} v^{2} \rho}{L^{2}}-m \omega^{2}\right)
$$

Equation (20) combined with data in Table 1 defines the critical velocity

$$
v_{c r}=\pi \sqrt{\frac{E J}{\rho L^{2}}}
$$

Figure 9 shows the comparison between the theoretical result expressed in Equation (20) and the numerical result of for the first frequency. The two results match, showing the good representation offered by a simple discretization of two elements in the finite element model. 


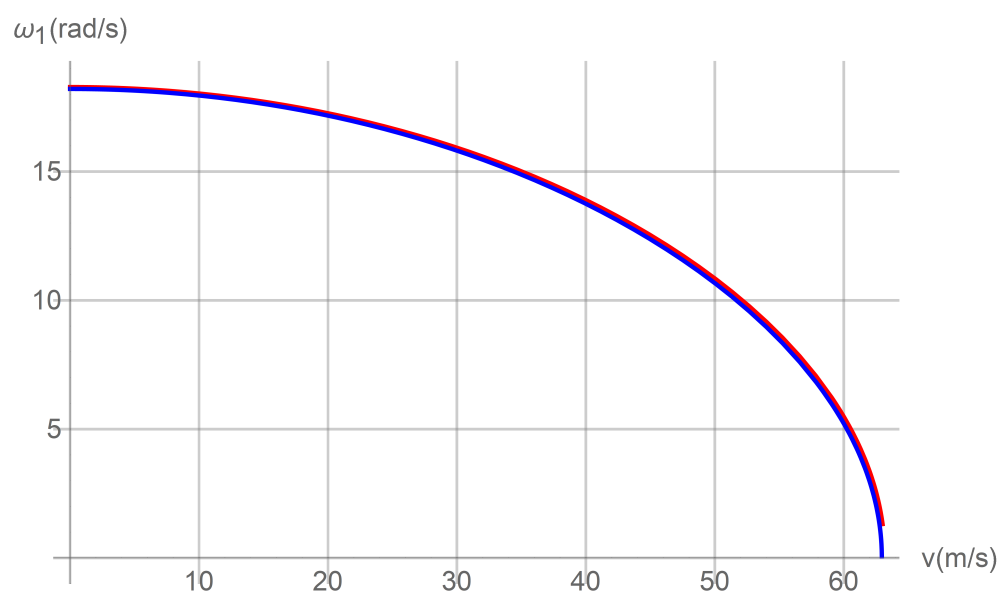

Figure 9. Frequencies with respect to the velocity.

In particular, Figure 10 shoes the error for the first frequency calculated as

$$
E r r=\left|\frac{\omega_{t}-\omega_{n}}{\omega_{t}}\right|
$$

where $w_{t}$ is the theoretical result of the frequency and $w_{n}$ is the numerical result.

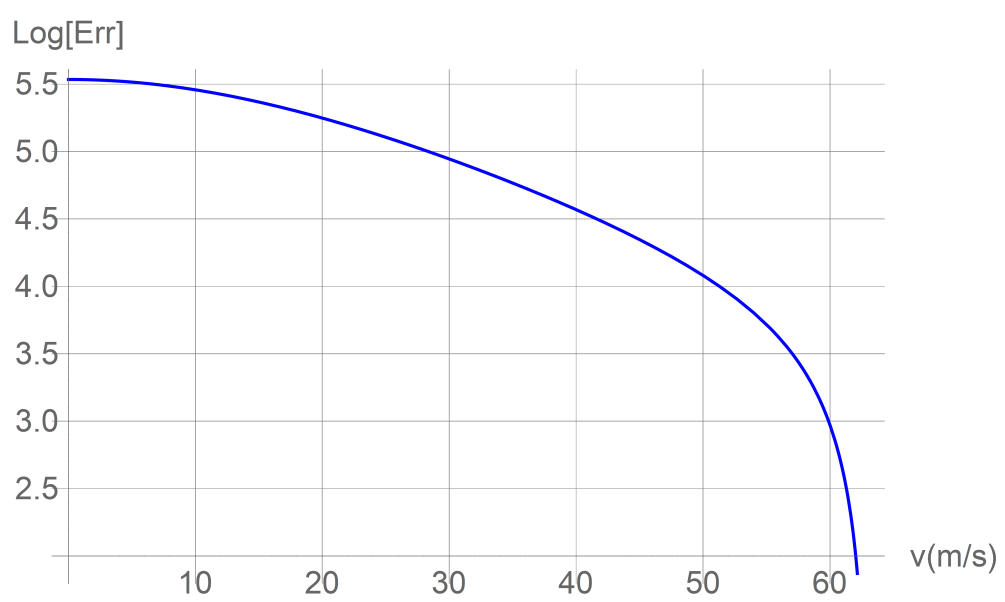

Figure 10. Error between theoretical and numerical result for the first frequency.

The error increases with the velocity as expected, suggesting the use of more elements for high velocities.

\section{Conclusions}

The analysis presented in this paper shows the importance of FEM in complex phenomena. In particular, a steel tube filled with a water under Coriolis forces is studied using two element in two different configurations. The results show how the FEM solution matches the analytical one using the Hermitian shape function especially for the first frequency. In particular, the elements used in this paper are mono-dimensional, since the problem is axial-symmetrical, leading to the most efficient discretization, considering the complexity and the number of elements. However, the results are not directly comparable with other method of application because similar examples of the effect of the Coriolis force on the vibration of the annulus pipe solved by FEM are lacking in the literature, it is proved that the first frequencies of the pipe for both configurations of the filled-with-water fixed pipe and hinged pipe are stackable for theoretical results as well as for the numerical results. Moreover, the extreme simplicity of the mesh leads to a fast solution for a complex 
mathematical problem, avoiding heavy three-dimensional meshes and difficult boundary impositions.

\section{Recommendations for Future Research}

A further study should be oriented to the stress distribution, as suggested in [34] in order to investigate mechanical aspects. The use of this method could be very apt to conjure approximate closed form solutions also for nonlinear problems. Further studies and applications could be aimed also at solving the problem applied to cylindrical shell conveying fluids, whose dynamic behavior is of practical interest in the field of power plants or oil pipelines. Cylindrical shells are essential structural elements in offshore structures, submarines, and airspace crafts. They are often subjected to combined compressive stress and external pressure, and therefore must be designed to meet strength requirements [35]. As discussed in [36], these structures are often stiffened by frames or ribs. Calculation of the sound scattering properties of stiffened circular shapes is difficult. Much research has focused on the acoustic radiation from a stiffened infinite shell with a simple shape but, when the shape is more complicated, such as for a submarine or an aircraft, the numerical methods are not appropriate, while the finite element method seems justified with the finite element characterizing the stiffeners. This phenomenon could be applied to modern tools such as Virtual or Augmented Reality. In particular, Augmented Reality (AR) is a computer technology where the perception of the user is enhanced by the seamless blending between a realistic environment and computer-generated virtual objects coexisting in the same space. The resulting mixture supplements reality, rather than replacing it. The possibility of interacting with external information could be very useful in simulations difficult to be interpreted by common users. As suggested in [37-47], Augmented Reality applications could have many interesting advantages and could be a viable tool in many fields now investigated by Industry 4.0 .

Author Contributions: Conceptualization F.C.; methodology and writing G.M.S.; writing and validation D.F. All authors have read and agreed to the published version of the manuscript.

Funding: This research received no external funding.

Conflicts of Interest: The authors declare no conflict of interest.

$\begin{array}{ll}\text { Abbreviations } \\ \text { FEM } & \text { Finite Element Method } \\ \text { LNG } & \text { Liquefied Natural Gas } \\ \text { LES } & \text { Large Eddy Simulations } \\ \text { CTN } & \text { Carbon NanoTubes } \\ \text { SEM } & \text { Spectral Element Method } \\ \text { SWCNT } & \text { Single-Walled Carbon NanoTubes } \\ \text { FSI } & \text { Fluid Structure Interaction } \\ \text { AR } & \text { Augmented Reality }\end{array}$

\section{References}

1. Ibrahim, R.A. Overview of Mechanics of Pipes Conveying Fluids_Part I: Fundamental Studies. J. Press. Vessel. Technol. $2010,132$. [CrossRef]

2. Paidoussis, M. Fluid-Structure Interactions: Slender Structures and Axial Flow; Academic Press: Cambridge, MA, USA, 2004; Volume 2.

3. Lee, U. Spectral element modelling and analysis of a pipeline conveying internal unsteady fluid. J. Fluids Struct. 2006, 22, 273-292. [CrossRef]

4. Dodds, H.L.; Runyan, H.L. Effect of High Velocity Fluid Flow on the Bending Vibrations and Static Divergence of a Simply Supported Pipe; National Aeronautics and Space Administration: Washington, DC, USA, 1965.

5. Yamaguchi, R.; Tanaka, G.; Liu, H.; Hayase, T. Fluid Vibration Induced in T-Junction with Double Side Branches. World J. Mech. 2016, 6, 169-179. [CrossRef]

6. Kuiper, G.; Metrikine, A. On stability of a clamped-pinned pipe conveying fluid. Heron 2004, 49, 211-232. 
7. Chellapilla, K.R.; Simha, H. Vibrations of Fluid-Conveying Pipes Resting on Two-parameter Foundation. Open Acoust. J. 2008, 1, 24-33. [CrossRef]

8. $\quad$ Leklong, J.; Chucheepsakul, S.; Kaewunruen, S. Dynamic Responses of Marine Risers/Pipes Transporting Fluid Subject to Top End Excitations; Faculty of Engineering, UOW: Wollongong, Australia, 2008.

9. Murai, M.; Yamamoto, M. An Experimental Analysis of the Internal Flow Effects on Marine Risers. Proc. MARTEC 2010, 1, 159-165.

10. Marakala, N.; Kuttan, A.K.K.; Kadoli, R. Experimental and Theoretical Investigation of Combined Effect of Fluid and Thermal Induced Vibration on Vertical Thin Slender Tube. Iosr J. Mech. Civ. Eng. 2013, 63-68.

11. Eriksson, O.; Breton, S.P.; Nilsson, K.; Ivanell, S. Impact of Wind Veer and the Coriolis Force for an Idealized Farm to Farm Interaction Case. Appl. Sci. 2019, 9, 922. [CrossRef]

12. Shaik, I.; Uddien, S.; Arkanti, K.; Sutar, S. Numerical Analysis of Clamped Fluid Conveying Pipe. HAL 2017. 64.857. [CrossRef]

13. Kokare, A.B.; Paward, P.M. Vibration Characteristics of Pipe Conveying Fluid. Int. J. Sci. Eng. Technol. Res. 2015, 4, 10951-10954.

14. Li, G.; Liu, J.; Jiang, G.; Kong, J.; Xie, L.; Xiao, W.; Zhang, Y.; Cheng, F. The nonlinear vibration analysis of the fluid conveying pipe based on finite element method. Comput. Model. New Technol. 2014, 18, 19-24.

15. Li, G.; Xiao, W.; Jiang, G.; Liu, J. Finite element analysis of fluid conveying pipe line of nonlinear vibration response. Comput. Model. New Technol. 2014, 18, 37-41.

16. Jweeg, M.J.; Ntayeesh, T.J. Dynamic analysis of pipes conveying fluid using analytical, numerical and experimental verification with the aid of smart materials. Int. J. Sci. Res. 2015, 4, 1594-1605.

17. Yi, X.; Li, B.; Wang, Z. Vibration Analysis of Fluid Conveying Carbon Nanotubes Based on Nonlocal Timoshenko Beam Theory by Spectral Element Method. Nanomaterials 2019, 9, 1780. [CrossRef]

18. Ferras, D.; Manso, P.; Schleiss, A.; Covas, D. One-Dimensional Fluid-Structure Interaction Models in Pressurized Fluid-Filled Pipes: A Review. Appl. Sci. 2018, 8, 1844. [CrossRef]

19. Elishakoff, I. Controversy Associated with the So-Called "Follower Forces": Critical Overview. Appl. Mech. Rev. 2005, 58, 117. [CrossRef]

20. Öz, H.R.; Boyaci, H. Transverse vibrations of tensioned pipes conveying fluid with time-dependent velocity. J. Sound Vib. 2000, 236, 259-276. [CrossRef]

21. Szmidt, T.; Przybyłowicz, P. Critical flow velocity in a pipe with electromagnetic actuators. J. Theor. Appl. Mech. 2013, 51, 487-496.

22. Askarian, A.; Abtahi, H.; Haddadpour, H. Dynamic instability of cantilevered composite pipe conveying flow with an end nozzle. In Proceedings of the 21st International Congress on Sound and Vibration 2014, ICSV 2014, Beijing, China, 13-17 July 2014; Volume 4, pp. 3564-3571.

23. Ntayeesh, T.; Alhelli, A. Free Vibration Characteristics of Elastically Supported Pipe Conveying Fluid. J. Eng. Sci. 2013, 16, 9-19.

24. Guo, Q.; Zhang, L.; Xiao, L. Damage analysis of the vehicle's pipe conveying fluid induced by complex random-shock loads. J. Press. Equip. Syst. 2006, 4, 100-103.

25. Zhang, Y.L.; Gorman, D.G.; Reese, J.M.; Horacek, J. Observations on the vibration of axially tensioned elastomeric pipes conveying fluid. J. Mech. Eng. Sci. 2000, 214, 423-434. [CrossRef]

26. Modarres-Sadeghi, Y.; Païdoussis, M. Nonlinear dynamics of extensible fluid conveying pipes, supported at both ends. J. Fluids Struct. 2009, 25, 535-543. [CrossRef]

27. Sharma, J.; Najafi, M.; Marshall, D.; Kaushal, V.; Hatami, M. Development of a Model for Estimation of Buried Large-Diameter Thin-Walled Steel Pipe Deflection due to External Loads. J. Pipeline Syst. Eng. Pract. 2019, 10. [CrossRef]

28. Malek Mohammadi, M.; Najafi, M.; Kermanshachi, S.; Kaushal, V.; Serajiantehrani, R. Factors Influencing the Condition of Sewer Pipes: A State-of-the-Art Review. J. Pipeline Syst. Eng. Pract. 2020, 11. [CrossRef]

29. Olunloyo, V.O.S.; Osheku, C.A.; Olayiwola, P.S. A Note on an Analytic Solution for an Incompressible Fluid Conveying Pipeline System. Adv. Acoust. Vib. 2017, 2017, 20. [CrossRef]

30. Paidoussis, M.; Issid, N. Dynamic stability of pipes conveying fluid. J. Sound Vib. 1974, 33, 267-294. [CrossRef]

31. Semler, C.; Li, G.; Paidoussis, M. The Non-linear Equations of Motion of Pipes Conveying Fluid. J. Sound Vib. 1994, 169, 577-599. [CrossRef]

32. Enz, S.; Thomsen, J.J. Predicting phase shift effects for vibrating fluid conveying pipes due to Coriolis forces and fluid pulsation. J. Sound Vib. 2011, 330, 5096-5113. [CrossRef]

33. Bathe, K. Finite Element Procedures in Engineering Analysis; Prentice Hall Inc.: Upper Saddle River, NJ, USA, 2014.

34. Zachwieja, J. Stress analysis of vibrating pipelines. Aip Conf. Proc. 2017, 1822, 020017. [CrossRef]

35. Bai, Y.; Jin, W.L. Ultimate Strength of Cylindrical Shells; Elsevier: Oxford, UK, 2016; pp. 353-365. [CrossRef]

36. Debus, J.C. 4-Finite element analysis of flexural vibration of orthogonally stiffened cylindrical shells with ATILA. In Applications of ATILA FEM Software to Smart Materials; Uchino, K., Debus, J.C., Eds.; Woodhead Publishing Series in Electronic and Optical Materials; Woodhead Publishing: New Delhi, India, 2013; pp. 69-93. [CrossRef]

37. Ceruti, A.; Marzocca, P.; Liverani, A.; Bil, C. Maintenance in aeronautics in an Industry 4.0 context: The role of Augmented Reality and Additive Manufacturing. J. Comput. Des. Eng. 2019, 6, 516-526. [CrossRef] 
38. Osti, F.; Ceruti, A.; Liverani, A.; Caligiana, G. Semi-automatic Design for Disassembly Strategy Planning: An Augmented Reality Approach. In Proceedings of the 27th International Conference on Flexible Automation and Intelligent Manufacturing, FAIM2017, Modena, Italy, 27-30 June 2017; Volume 11, pp. 1481-1488. [CrossRef]

39. Frizziero, L.; Liverani, A.; Caligiana, G.; Donnici, G.; Chinaglia, L. Design for disassembly (DfD) and augmented reality (AR): Case study applied to a gearbox. Machines 2019, 7, 29. [CrossRef]

40. De Marchi, L.; Ceruti, A.; Marzani, A.; Liverani, A. Augmented Reality to Support On-Field Post-Impact Maintenance Operations on Thin Structures. J. Sens. 2013, 2013, 619570. [CrossRef]

41. Liverani, A.; Leali, F.; Pellicciari, M. Real-time 3D features reconstruction through monocular vision. Int. J. Interact. Des. Manuf. 2010, 4, 103-112. [CrossRef]

42. Liverani, A.; Kuester, F.; Hamann, B. Towards interactive finite element analysis of shell structures in virtual reality. In Proceedings of the 1999 IEEE International Conference on Information Visualization (Cat. No. PR00210), London, UK, 14-16 July 1999; pp. 340-346. [CrossRef]

43. Francia, D.; Seminerio, D.; Caligiana, G.; Frizziero, L.; Liverani, A.; Donnici, G. Virtual Design for Assembly Improving the Product Design of a Two-Way Relief Valve. In Proceedings of the International Conference on Design, Simulation, Manufacturing: The Innovation Exchange, Kharkiv, Ukraine, 9-12 June 2020; pp. 304-314. [CrossRef]

44. Osti, F.; Santi, G.C.G. Real Time Shadow Mapping for Augmented Reality Photorealistic Rendering. Appl. Sci. 2019, 9, 2225. [CrossRef]

45. Francia, D.; Ponti, S.; Frizziero, L.; Liverani, A. Virtual Mechanical Product Disassembly Sequences Based on Disassembly Order Graphs and Time Measurement Units. Appl. Sci. 2019, 9, 3638. [CrossRef]

46. Amicis, R.; Ceruti, A.; Francia, D.; Frizziero, L.; Simões, B. Augmented Reality for virtual user manual. Int. J. Interact. Des. Manuf. 2018, 12. [CrossRef]

47. Frizziero, L.; Donnici, G.; Caligiana, G.; Liverani, A.; Francia, D. Project of Inventive Ideas Through a TRIZ Study Applied to the Analysis of an Innovative Urban Transport Means. Int. J. Manuf. Mater. Mech. Eng. 2018, 8, 35-62. [CrossRef] 